\title{
Influence of Relative Humidity on the Temperature Increase of a Power Converter
}

\author{
Yang $\mathrm{Xu}^{*}$, Hao Chen ${ }^{\dagger}$, Zhentao $\mathrm{Hu}^{*}$, and Dong $\mathrm{Li}^{*}$ \\ ${ }^{\dagger *}$ School of Information and Electrical Engineering, China University of Mining and Technology, Xuzhou, China
}

\begin{abstract}
As a vital part of renewable energy and electrical traction, power converters are supposed to have high reliability and good performance. However, power semiconductors produce considerable heat when the power converter works, which results in high junction temperatures that lower the reliability and performance of the power semiconductors. Many studies show that ambient humidity has a significant effect on power devices, but the influence of high humidity on junction temperatures has yet to be studied. Therefore, this paper presents a thermal model for power converters in moist air to obtain the junction temperature increase, which is utilized for the power converter used in a Switched Reluctance Motor System. Simulation results show that the law of converter temperature distribution is independent of the relative humidity in the case of fixed ambient temperature, whereas the temperature in the power converter decreases as the ambient relative humidity increases. These simulation results are validated with the experimental results.
\end{abstract}

Key words: Moist air, Power converter, Relative humidity, Switched reluctance motor system, Thermal model

\section{INTRODUCTION}

Power converters are widely used in various fields, such as renewable energy generation, electric motor traction, and power transformers. However, power semiconductor devices in power converters have high failure rates. The reasons semiconductor devices fail include temperature (55\%), vibration (20\%), humidity (19\%), and dust (6\%) [1]-[3]. Unfortunately, in some circumstances, power converters are used in high-humidity environments, such as coal mines. For example, the relative humidity in some coal mines is higher than $94 \%$, with the temperature as much as $35^{\circ} \mathrm{C}$.

The device characteristics of a power converter in such conditions are different from those in normal environments. On the one hand, a highly humid environment makes the semiconductor devices frequently invalid because of corrosion, electromigration, and moisture absorption [4]-[7]. On the other hand, a high-temperature environment can cause the device to have a high junction temperature. Once the device junction temperature exceeds the maximum junction temperature, the

Manuscript received Dec. 2, 2014; accepted Jan. 29, 2015

Recommended for publication by Associate Editor Sang-Won Yoon.

${ }^{\dagger}$ Corresponding Author: hchen@cumt.edu.cn

Tel: +86-130-1399-3107, Fax: +86-0516-83884587, China University of Mining and Technology

* School of Information and Electrical Engineering, China University of Mining and Technology, China device becomes invalid. The device junction temperature has a significant influence on its characteristics and lifetime [8]-[12]. Variations in ambient humidity can also change the device junction temperature, which influences device performance and reliability.

Nowadays, almost every device manual provides temperature and humidity ranges for safe operation. However, studies on the heat transfer performance of power converters in highly humid environments are limited. Therefore, the present study focuses on the influence of highly humid environments on the temperature increases of power semiconductor devices. First, the physical descriptions of a power converter in a humid environment are presented based on a power converter used in the Switched Reluctance Motor (SRM) system [13]-[19]. Second, mathematical equations are presented to describe the power converter in a humid environment. A simplified thermal model is then proposed and implemented in Finite Element Method (FEM) software based on the said equations. The simulation results of the device junction temperatures under different ambient relative humidity levels are derived. Finally, the experiment platform is established to prove the correctness of the thermal model and simulation results.

\section{DESCRIPTION OF A POWER CONVERTER IN A HUMID ENVIRONMENT}




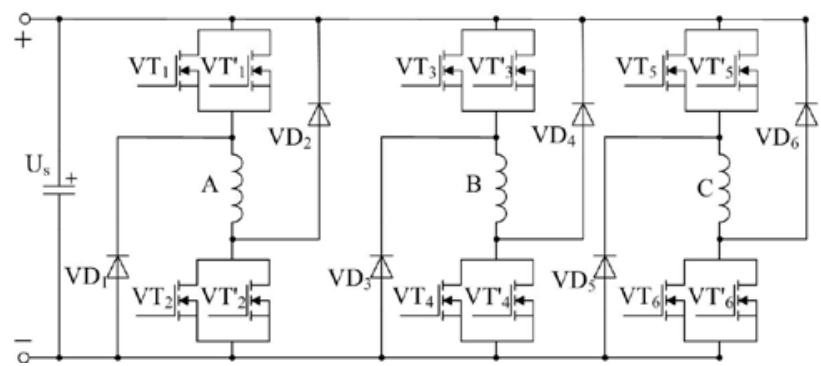

Fig. 1. Main circuit topology.

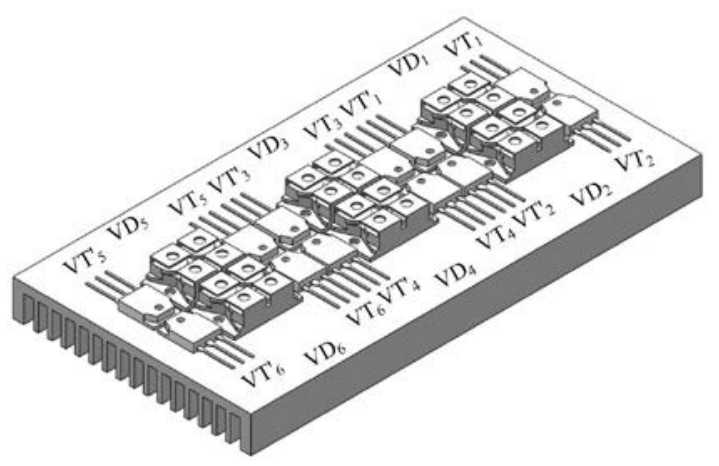

Fig. 2. Structure of the SRM power converter.

TABLE I

DiMENSIONS OF THE HEAT SiNK (UNIT: mm)

\begin{tabular}{ccccc}
\hline Length & Width & Height & Fin height & Fin spacing \\
\hline 250 & 132 & 20 & 15 & 2.6 \\
\hline
\end{tabular}

\section{A. SRM Power Converter}

A power converter used in the SRM system is taken as an example to study the heat transfer performance of the power converter in a humid environment. The topology of the main circuit is shown in Fig. 1, which adopts the three-phase asymmetric half-bridge circuit.

The corresponding structure of the power converter is illustrated in Fig. 2. Two power MOSFETs (FAIRCHILD FQA160N08) are connected in parallel as a half bridge, such as $V T_{1}$ and $V T^{\prime}{ }_{1}$, and located on each side of a diode, as shown in Fig. 2, to lower costs. A fast recovery diode (IXYS DSEI 2x121) is applied as the freewheeling diode.

The power semiconductor devices are mounted on a heat sink made of aluminum alloy. Its dimensions are listed in Table I. The heat sink is in a natural air-cooling condition.

The power converter is used to drive a 12/8 SRM. The alternative Pulse Width Modulation (PWM) is applied for the control signal, where the PWM signals are used alternately on the upper and lower transistors. Therefore, all devices have the same power loss, which becomes the input to the thermal model as heating power [20].

\section{B. Physical Description of Humid Environment}

In this study, the SRM system is installed in a large but humid space, so the dissipation of the heat generated from the power converter relies on the motion of the moist air.
Moist air is a mixture of dry air and water vapor. Absolute Humidity ( $\mathrm{AH})$ and Relative Humidity $(\mathrm{RH})$ are applied to measure moist air. $\mathrm{AH}$ is the mass of water vapor divided by the volume of moist air with the unit of $\mathrm{mg} / \mathrm{L}$, whereas $\mathrm{RH}$ is the ratio of partial pressure of water vapor to the equilibrium vapor pressure of water at the same temperature expressed as a percentage (\%). $\mathrm{RH}$ reflects the distance to the saturated moist air. Thus, RH is more useful for equipment safety and human health than $\mathrm{AH}$.

When the power converter operates in a natural air-cooling condition, the energy loss from the power devices heats the surrounding air, which results in the variation in air density. The air near the power converter has a high temperature, which means that the air molecules have large kinetic energy. Thus, these parts of the air have small densities, whereas the air far from the power converter has a large density according to the theory of thermodynamics. Therefore, buoyancy force is produced and drives the air to move, a process called heat convection.

Mass diffusion is another phenomenon that occurs in the air. This phenomenon occurs because of the concentration gradient of air molecules, including water vapor molecules. Air molecules in the large-density region move to the small-density region.

Therefore, heat convection and mass diffusion compose the entire heat transfer process. Given that the space is much larger than the power converter itself, the environmental temperature, pressure, and $\mathrm{AH}$ are constant.

\section{HeAt Transfer MOdEL IN MOIST AIR}

Heat transfer between solids and fluids belongs to the convective heat transfer problem, which can generally be solved by the heat transfer differential equation set. This set includes mass conservation, momentum conservation, and energy conservation equations. However, the component conservation equation should be added to describe the moist air in this case, which has two components.

\section{A. Mass Conservation Equation}

The law of conservation of mass states that if the fluid is continuous, then the mass change rate with time will be equal to the mass flow difference of the inflow and outflow to determine the mass volume without sources. This factor can be expressed as follows:

$$
\frac{\partial \rho}{\partial t}+\frac{\partial(\rho u)}{\partial x}+\frac{\partial(\rho v)}{\partial y}+\frac{\partial(\rho w)}{\partial z}=0
$$

where $\rho$ is the density, $t$ is the time, and $u, v$, and $w$ represent the components of the velocity vector $U$ in the $\mathrm{x}, \mathrm{y}$, and $\mathrm{z}$ directions, respectively.

\section{B. Momentum Conservation Equation}

The momentum differential equations of fluid motion, which is Newton's second law, can be described as follows. The 
momentum change rate with time in the fluid is equal to the sum of external forces on the fluid in a determining volume. Thus, this rate can be expressed as follows:

$$
\left\{\begin{array}{l}
\frac{\partial(\rho u)}{\partial t}+\operatorname{div}(\rho u U)=\frac{\partial \tau_{x x}}{\partial x}+\frac{\partial \tau_{y x}}{\partial y}+\frac{\partial \tau_{z x}}{\partial z}+\rho g_{x} \\
\frac{\partial(\rho v)}{\partial t}+\operatorname{div}(\rho v U)=\frac{\partial \tau_{x y}}{\partial x}+\frac{\partial \tau_{y y}}{\partial y}+\frac{\partial \tau_{z y}}{\partial z}+\rho g_{y} \\
\frac{\partial(\rho w)}{\partial t}+\operatorname{div}(\rho w U)=\frac{\partial \tau_{x z}}{\partial x}+\frac{\partial \tau_{y z}}{\partial y}+\frac{\partial \tau_{z z}}{\partial z}+\rho g_{z}
\end{array}\right.
$$

where $\tau$ is the components of viscous forces on the element surfaces because of molecular viscosity. The last term on the right is the gravity forces on the element.

\section{Energy Conservation Equation}

The temperature field in the convection heat transfer problem can mostly be described by the energy conservation equation. In particular, the total energy change rate with time in the fluid in a determining volume is equal to the sum of the net heat into the volume per unit time because of the heat convection and heat conduction. The work by forces on the interface of the volume per unit time can be expressed as follows:

$$
\frac{\partial(\rho T)}{\partial t}+\operatorname{div}(\rho \mathrm{u} T)=\operatorname{div}\left(\frac{k}{c_{p}} \operatorname{grad} T\right)+S_{T}
$$

where $c_{p}$ is the specific heat capacity, $T$ is the temperature, $k$ is the heat conduction coefficient of the fluid, and $S_{T}$ is the internal heat source. The second term on the left is the energy transformed from the viscous forces.

\section{Component Mass Conservation Equation}

The component mass conservation equation shows that each component in the system should satisfy the mass conservation equation. If the components in the system undergo a chemical reaction, then this equation will become complicated. However, no chemical reaction is involved in this study, so the component mass conservation equation can be expressed as follows:

$$
\frac{\partial\left(\rho Y_{i}\right)}{\partial t}+\nabla \cdot\left(\rho U Y_{i}\right)=0
$$

where $Y_{i}$ is the mass fraction of the $I_{t h}$ component, and the second term on the left is the mass variation caused by the mass diffusion.

\section{E. Simplification of the Thermal Model}

The above four equations with the corresponding boundary conditions can correctly describe the heat transfer problem in moist air condition and can obtain the motion details of each component in moist air. However, obtaining results even via FEM software is a complicated process. Therefore, a method is proposed to simplify the problem, that is, the moist air is regarded as an integral without considering the motion of the two components inside. Only the moist air properties are required.
Several assumptions are provided as follows to calculate the properties of moist air:

- Moist air is an ideal gas, including dry air and water vapor.

- No phase change occurs in the water vapor, that is, the water molecule only exists in gas state.

- The moist air pressure is standard atmosphere pressure at approximately $101 \mathrm{kPa}$.

- $\quad$ The moist air temperature is below $100{ }^{\circ} \mathrm{C}$.

Moist air properties include density, viscosity, specific heat, thermal conductivity, and Prandtl Number.

Moist air density is given by the following:

$$
\rho_{m}=\frac{P_{m}}{R_{d} T}\left(1-0.378 \frac{R H \cdot P_{s}}{P_{m}}\right)
$$

where $P_{m}$ is the pressure of the moist air, $R_{d}$ is equal to 287.06 $\mathrm{J} / \mathrm{kg} \cdot \mathrm{k}, P_{s}$ is the saturation pressure of the water vapor at temperature $T$, and $R H$ is the relative humidity.

Specific heat of the moist air is provided by the following:

$$
c_{m}=\frac{c_{d}}{1+d(t)}\left(1+d(t) \frac{c_{v}}{c_{d}}\right)
$$

where $c_{d}$ is the specific heat of dry air, $c_{v}$ is the specific heat of water vapor, and $d(t)$ is the moist content, which is the water vapor mass in $1 \mathrm{~kg}$ of dry air divided by $1 \mathrm{~kg}$.

The thermal conductivity of the moist air is provided by the following:

$$
k_{m}=\frac{Y_{d} k_{d}}{Y_{d}+Y_{v} A_{d}}+\frac{Y_{v} k_{v}}{Y_{v}+Y_{d} A}
$$

where $Y_{d}$ is the mole fraction of dry air, $Y_{v}$ is the mole fraction of water vapor, $k_{d}$ is the thermal conductivity of dry air, $k_{v}$ is the thermal conductivity of water vapor, and $A_{d}$ and $A_{v}$ are the combination parameters.

Moist air viscosity is provided by the following:

$$
\mu_{m}=\mu_{d} \frac{1+1.268 \frac{\mu_{v}}{\mu_{d}} d(t)}{1+1.268 d(t)}
$$

where $\mu_{v}$ is the viscosity of water vapor, $\mu_{d}$ is the viscosity of dry air, and $d(t)$ is the moist content.

The Prandtl Number of the moist air is provided by the following:

$$
P_{r}=\frac{\mu_{m} c_{m}}{\lambda_{m}}
$$

Consequently, the moist air properties can be derived based on Eqs. (5) to (9). Eq. (4) is not required, and Eqs. (1) to (3) are sufficient to describe the problem. Given the complicated object geometry and strong nonlinearity of the equations, the thermal model is implemented in the CFX software to obtain the temperature distributions of the power converter.

\section{NUMERICAL SOLUTIONS}

ANSYS/CFX is the Computational Fluid Dynamics (CFD) software that can resolve fluid mechanics, heat transfer, 
combustion, and fluid-structure coupling problems using FEM to solve mass conservation, momentum conservation, energy conservation equations.

\section{A. Physical Structure}

The simulation model is built in the CFX software to describe the power converter in a humid environment, where the power converter is placed in a cube measuring $0.5 \mathrm{~m} \times 0.5$ $\mathrm{m} \times 0.5 \mathrm{~m}$ filled with moist air. Unlike the power converter, the cube size is sufficiently large. The entire model is divided into two parts, the fluid (moist air) and solid parts (power converter).

\section{B. Meshing}

The tetrahedron mesh element is applied to mesh the solid and fluid domains using the professional meshing software ICEM CFD. Given a large dimension range among the semiconductor devices, heat sink, and moist air, a mixture meshing method with different grid sizes is used. For example, a denser grid is applied for the moist air around the power converter. The denser grid is also used where a large gradient in terms of temperature, heat flow density, and fluid velocity exists. The grid density gradually decreases with a center ratio from the inside to the outside.

\section{Physical Properties and Boundary Conditions}

Several suitable assumptions are provided as follows to simplify the problem.

- All materials are thermally homogeneous and isotropic.

- $\quad$ The material thermal properties are independent of temperature.

- No thermal contact resistance exists between any material.

- $\quad$ Thermal radiation is ignored.

The thermal conductivities of the heat sink, power MOSFET, and power diode are $237 \mathrm{~W} /(\mathrm{m} \cdot \mathrm{k}), 52 \mathrm{~W} /(\mathrm{m} \cdot \mathrm{k})$, and $42 \mathrm{~W} /(\mathrm{m} \cdot \mathrm{k})$, respectively.

The moist air properties with different temperature and different relative humidity levels can be calculated from Eqs. (5) to (9).

The heating power of the power MOSFET is $1.75 \mathrm{~W}$, and the heating power of the power diode is $0.15 \mathrm{~W}$.

The six faces in the cube are set as no-slip walls with the fixed temperature equal to the initial ambient temperature.

\section{Simulation Results}

The air temperature was first fixed at $10^{\circ} \mathrm{C}, 20^{\circ} \mathrm{C}$, and $30{ }^{\circ} \mathrm{C}$ to study the heat transfer performance of the power converter with the moist air. The $\mathrm{RH}$ changed from $50 \%$ to $90 \%$ with $10 \%$ intervals at each temperature to study its influence on the temperature increase of the power converter. A high RH environment has a negative impact on the power
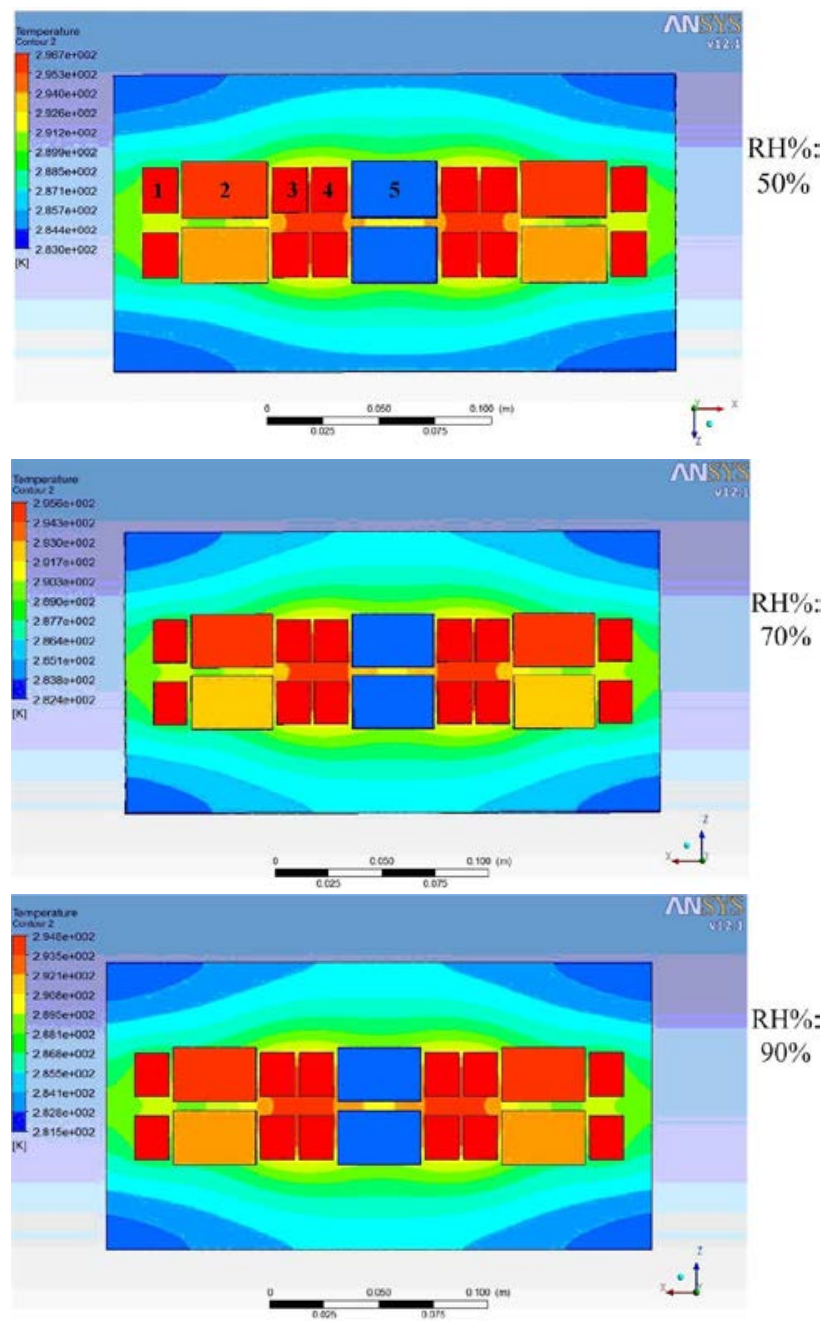

Fig. 3. Temperature increase distribution of the power converter in different $\mathrm{RH}$ levels in $30^{\circ} \mathrm{C}$ ambient temperature.

converter and air characteristics with 100\% change from normal and the existence of liquid water; hence, the $\mathrm{RH}$ range for this research is set from $50 \%$ to $90 \%$. The temperature increase is equal to the temperature minus the ambient temperature. Given that the ambient temperature is changed in each case, the device junction temperature cannot reflect the heat performance. However, the device junction temperature increase is independent from the ambient temperature. Therefore, the temperature increase is applied to scale the heat transfer performance.

Fig. 3 presents the simulation results of the temperature distributions of the power converter in 50\%, 70\%, and $90 \%$ of the ambient $\mathrm{RH}$ in the case of the $30{ }^{\circ} \mathrm{C}$ ambient temperature. The proposed thermal model shows that the device junction temperatures are only on the device surfaces. When the ambient $\mathrm{RH}$ is $50 \%$, the highest junction temperature increase is $23.7{ }^{\circ} \mathrm{C}$ in the middle MOSFET. The highest junction temperature decreases when the ambient $\mathrm{RH}$ increases (e.g., $22.6{ }^{\circ} \mathrm{C}$ in $70 \%$ and $21.8{ }^{\circ} \mathrm{C}$ in $90 \%$ ). The reason for this condition is that the moist air flow intensifies as the $\mathrm{RH}$ 


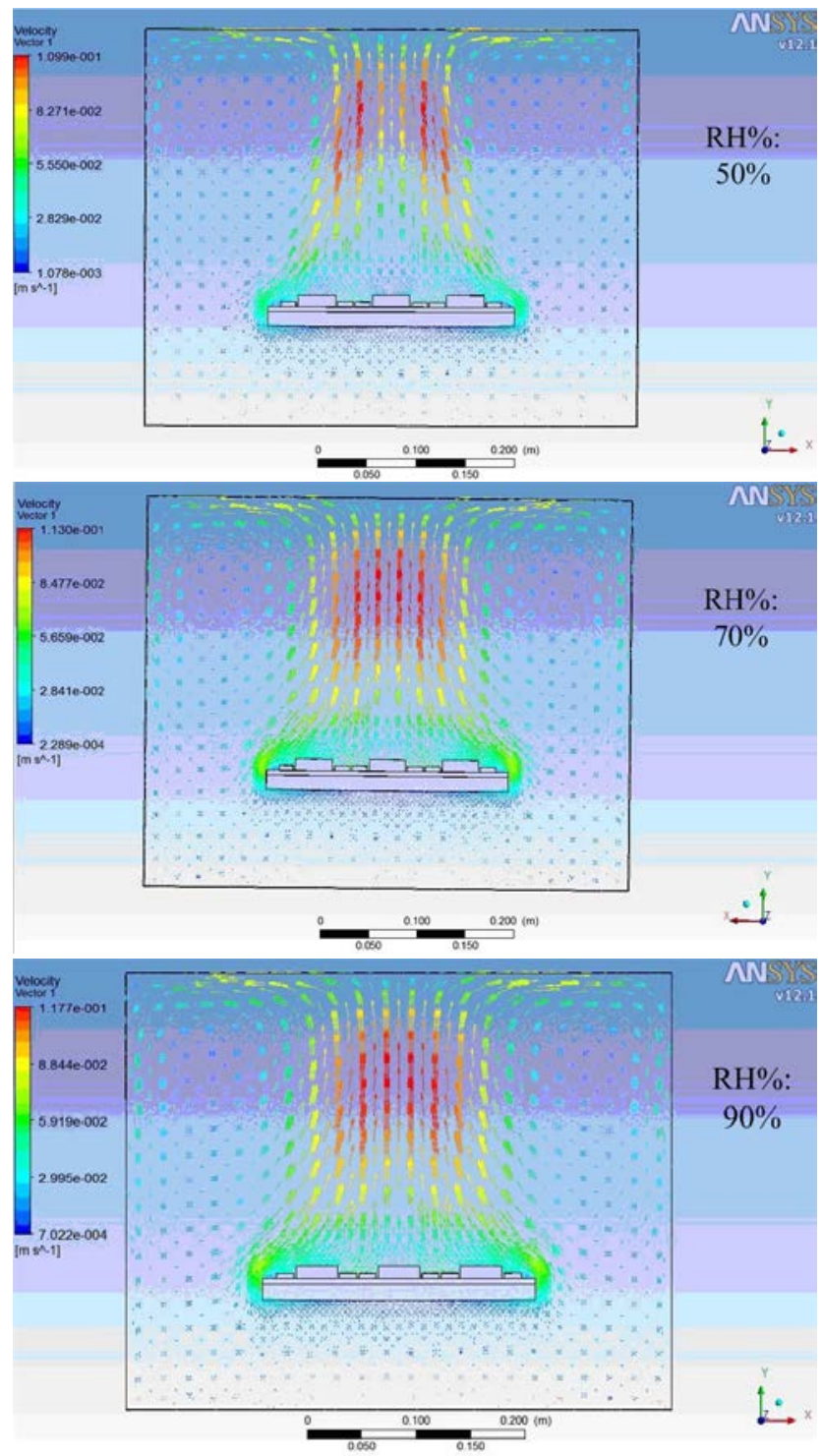

Fig. 4. Velocity distribution of the moist air in the cube in different $\mathrm{RH}$ levels in $30^{\circ} \mathrm{C}$ ambient temperature.

increases in Fig. 4. For example, the highest flowing velocity of moist air is approximately $0.11 \mathrm{~m} / \mathrm{s}$ in $50 \%$, whereas it becomes approximately $0.12 \mathrm{~m} / \mathrm{s}$ in $90 \%$ where the heat transfer performance is strengthened.

However, the temperature increase distribution is unchanged in Fig. 3 with the RH variation. The temperature distribution is symmetric, the middle MOSFETs have higher temperature, and the marginal MOSFETs have lower temperature. The diode with the lowest temperature is in the middle. The junction temperature increases of the five devices in different ambient $\mathrm{RH}$ levels in $30^{\circ} \mathrm{C}$ are shown in Fig. 5. The device number is shown in Fig. 3. Simulation results show that the $\mathrm{RH}$ does not change the device temperature increase distribution of the power converter.

Therefore, only the highest temperature increase should be analyzed. Fig. 6 presents the relationships between the highest

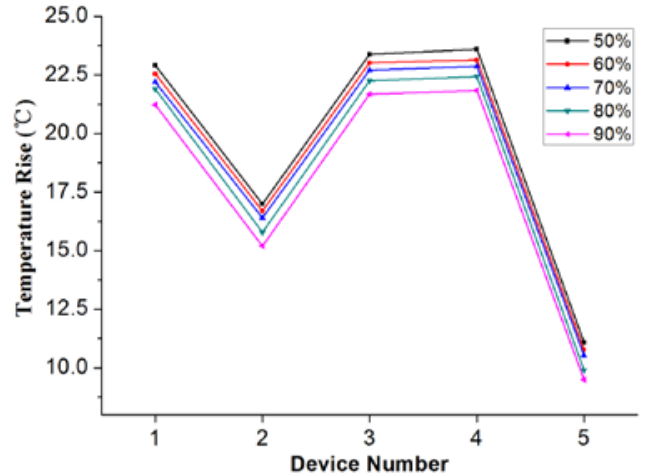

Fig. 5. Device temperature increases in different $\mathrm{RH}$ levels in $30{ }^{\circ} \mathrm{C}$ ambient temperature.

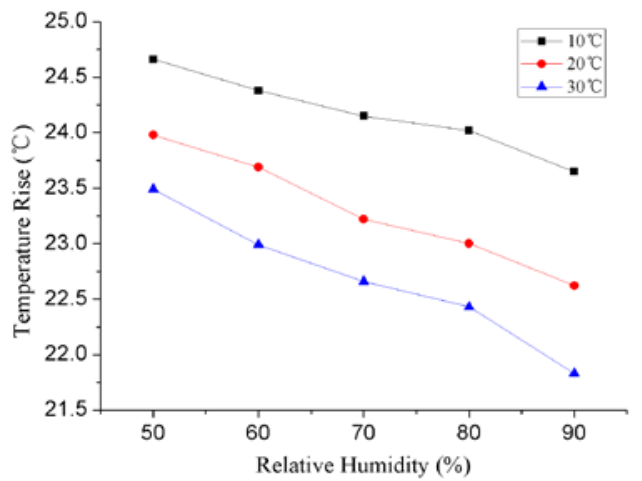

Fig. 6. Relationship of $\mathrm{RH}$ and temperature increase from the simulation results.

temperature increases and $\mathrm{RH}$ under different ambient temperatures. This figure shows that the highest temperature decreases with the ambient $\mathrm{RH}$ that increases under the same ambient temperature. The highest temperature increase of the power converter also decreases with the ambient temperature that increases under the same ambient RH.

\section{EXPERIMENT AND VALIDATION}

\section{A. Experiment Platform}

An experimental platform, which includes a designed temperature and humidity control box, SRM controller, and SRM motor, was designed (Fig. 7) to validate the simulation results. The box size is $1 \mathrm{~m} \times 1 \mathrm{~m} \times 1 \mathrm{~m}$ with suitable insulation performance. The box can be considered as a large space environment because it is larger than the power converter. Thus, the heating of the power converter has little influence on the air characteristics inside the box. Moreover, an internal heater and humidifier are regulated by a PID controller, so the box can maintain a specific temperature and $\mathrm{RH}$ level to simulate a humid environment.

A temperature measuring instrument was applied to measure the power converter temperature. It can provide 12 temperature test channels, and the corresponding 12 thermocouples are attached to the surfaces of the power MOSFETs as shown in 

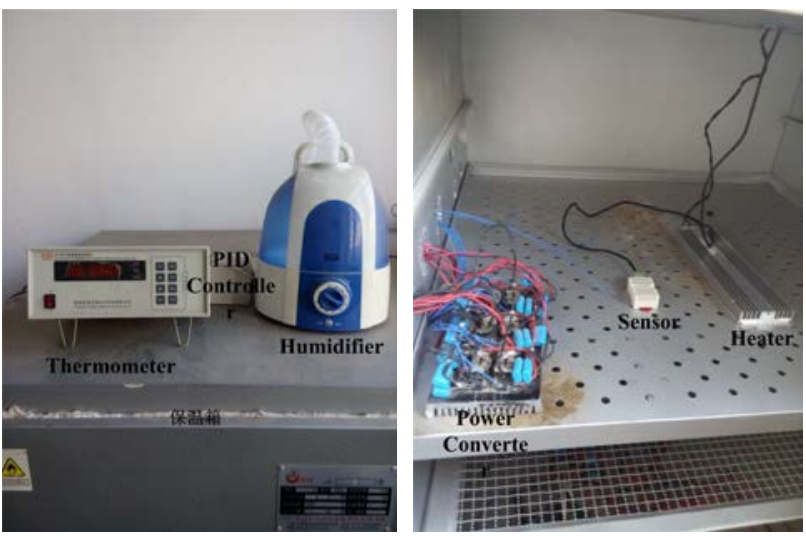

Fig. 7. Experiment platform.

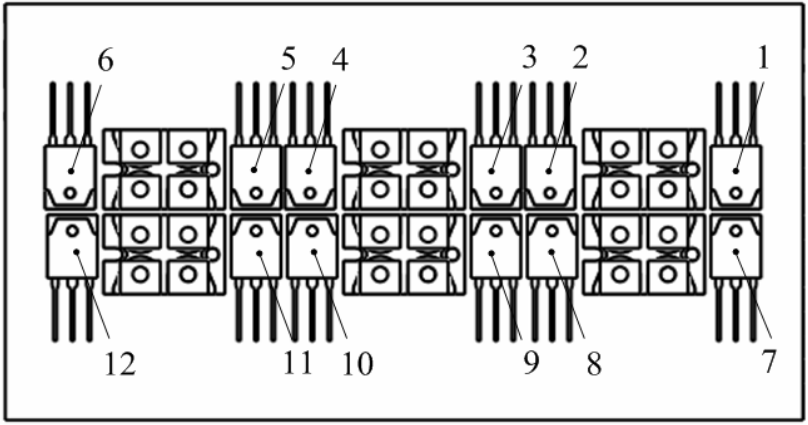

Fig. 8. Positions of the temperature test points.

Fig. 8. Sampling time is $1 \mathrm{~s}$. When the SRM runs steady or has a fixed speed, then the device temperature is measured. The temperature curves remain constant, and the device steady-state temperatures are obtained.

\section{B. Experiment Results}

Three cases were designed to validate the simulation results. To study the influence of the RH on heat transfer performance of the power converter, the air temperature inside the box was first set in each case, and then the $\mathrm{RH}$ of the inside air was changed.

1) Case 1: Moist air temperature is maintained at $10^{\circ} \mathrm{C}$ in this case, and moist air RH was changed to $70 \%, 80 \%$, and $90 \%$. The temperature increases of the power MOSFETs in the power converter were measured in each ambient RH level. The experimental results are shown in Fig. 9.

2) Case 2: Air temperature is $20{ }^{\circ} \mathrm{C}$ in this case, whereas air RH was also varied from $70 \%$ to $90 \%$ with $10 \%$ intervals. The experimental results of the device temperature increases in these conditions are shown in Fig. 10.

3) Case 3: Air temperature is maintained at $30{ }^{\circ} \mathrm{C}$ in this case, and the device temperature increases were measured as air $\mathrm{RH}$ changed as before. The experiment results are shown in Fig. 11.

First, verifying the temperature distribution of the power converter from the simulation is important. Thus, the simulated temperature increases of 12 power MOSFETs are compared

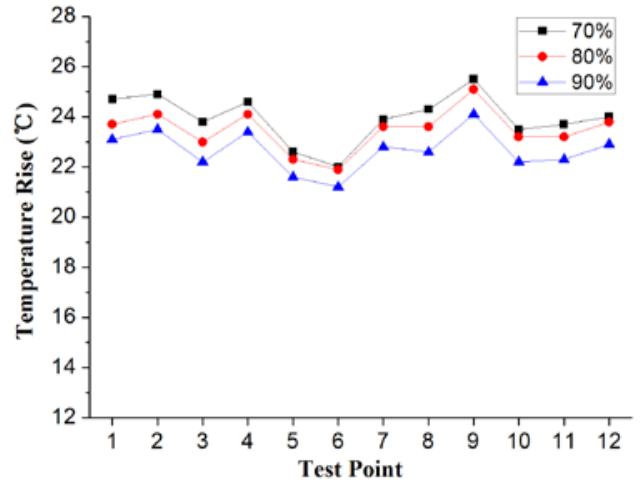

Fig. 9. Temperature increases of the MOSFETs at $10^{\circ} \mathrm{C}$.

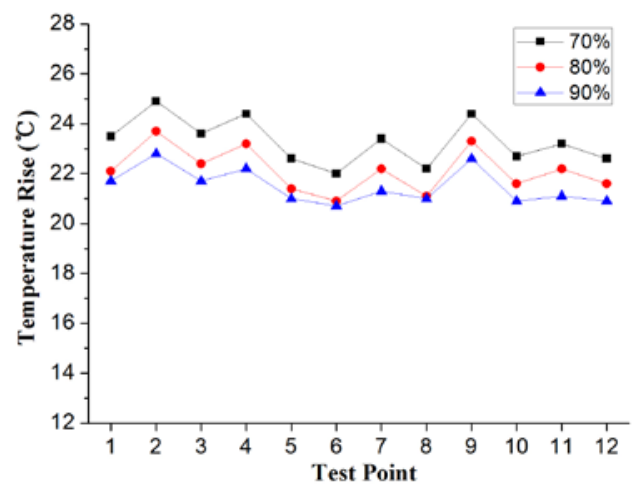

Fig. 10. Temperature increases of MOSFETs at $20^{\circ} \mathrm{C}$.

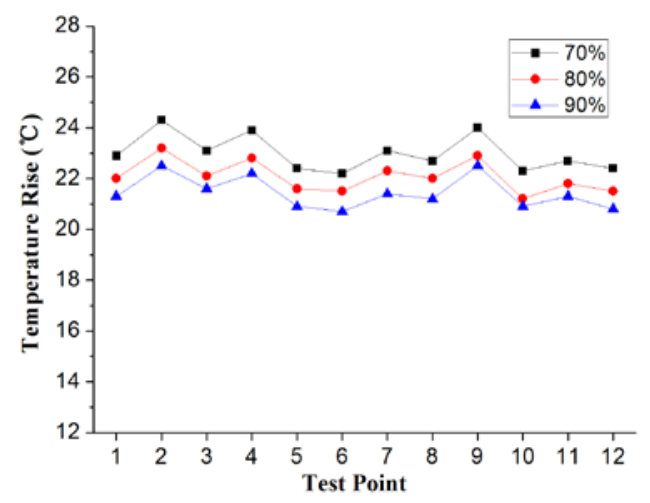

Fig. 11. Temperature increases of MOSFETs at $30^{\circ} \mathrm{C}$.

with the experimental results. Fig. 12 shows the comparison results at $30{ }^{\circ} \mathrm{C}$ as an example. Several errors between the simulation and experiment are observed because of the asymmetry characteristics between the devices in the experiment, including the different lengths of the connection and different stray parameters. Thus, their variation trends are basically the same, which verifies the correctness of the temperature distribution results from the simulation.

The experimental and simulated results also show that the $\mathrm{RH}$ does not influence temperature distributions among the devices regardless of ambient temperature. The highest temperature is then obtained for analysis as shown in Fig. 13. This figure presents the relationship between the highest 


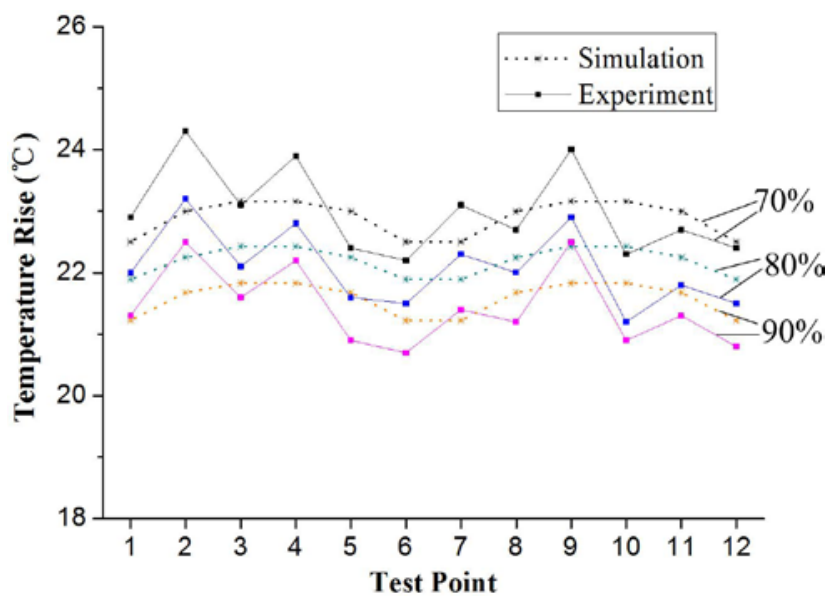

Fig. 12. Comparison of the simulated temperature distribution of the power converter and experimental model at $30^{\circ} \mathrm{C}$.

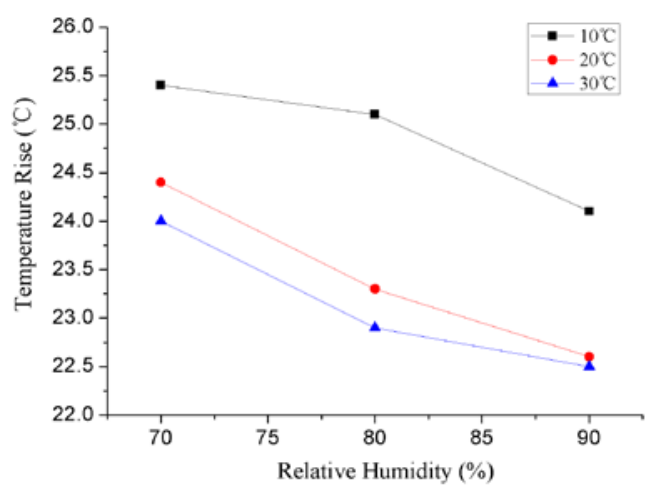

Fig. 13. Relationship of $\mathrm{RH}$ and temperature increase from experimental results.

temperature of the power converter and the ambient $\mathrm{RH}$ of moist air. The highest temperature decreases as the ambient $\mathrm{RH}$ increases in a fixed ambient temperature.

Comparing the simulation and experimental results (although these do not exactly match) shows that they have the same variation trend, which verifies the correctness of the simulation model. Two main reasons explain the differences between the simulation and the experiment. First, the simulation results are the junction temperature, whereas the experimental results are the surface temperature of the devices. Second, the heat transfer performance in simulation is stronger than the experiment because of the simplified thermal model, so the simulated junction temperatures are lower than the experimental ones.

Owing to the limitation of the experimental conditions, the simulated results at $60 \%$ and $50 \%$ are unverified by the experiment. However, the law of temperature variation from $50 \%$ to $90 \%$ is the same as in the simulation.

Thus, the simulation and experiment show that the heat transfer performance of the power converter is enhanced as the ambient RH decreases. However, the temperature distribution of the power converter is independent from the ambient $\mathrm{RH}$.

\section{CONCLUSION}

A highly humid environment has a significant effect on the temperature reliability of electrical equipment. This study uses an SRM power converter to study the influence of ambient $\mathrm{RH}$ on its heat transfer performance. First, the mathematical equations and a simplified thermal model for the power converter in a humid environment are proposed and implemented in the CFX software. The numerical solutions are derived on the basis of several suitable assumptions. Finally, the simulation results are validated by the designed experiment platform. The study results shows that a high ambient $\mathrm{RH}$ can decrease the temperature increases of the power converter, but does not influence its temperature distribution in fixed ambient temperature. The simulated results at $60 \% \mathrm{RH}$ and below can be verified by more advanced experimental platforms in the future, and the power converter characteristics at $100 \%$ can also be studied.

\section{ACKNOWLEDGMENT}

This study was supported by the Fundamental Research Funds for the Central Universities (China University of Mining and Technology) 2014ZDPY33 and A Project Funded by the Priority Academic Program Development of Jiangsu Higher Education Institutions. The authors express their sincere gratitude for such support.

\section{REFERENCES}

[1] W. Huai, M. Liserre, F. Blaabjerg, P. de Place Rimmen, J. B. Jacobsen, T. Kvisgaard, and J. Landkildehus, "Transitioning to physics-of-failure as a reliability driver in power electronics," IEEE J. Emerg. Sel. Topics Power Electron., Vol. 2, No. 1, pp.97-114, Mar. 2014.

[2] S. Yang, A. Bryant, and P. Mawby, D. Xiang, L. Ran, and $P$. Tavner, "An industry-based survey of reliability in power electronic converters," IEEE Trans. Industry Applications, Vol. 47, No. 3, pp.1441-1451, May./Jun. 2011.

[3] H. Behjati and A. Davoudi, "Reliability analysis framework for structural redundancy in power semiconductors,” IEEE Trans. Ind. Electron., Vol. 60, No. 10, pp.4376-4386, Oct. 2013.

[4] R. Ciprian and B. Lehman, "Modeling effects of relative humidity, moisture, and extreme environmental conditions on power electronic performance," IEEE Energy Conversion Congress and Exposition, pp.1052-1059, 2009.

[5] H. Abbad, S. Azzopardi, E. Woirgard, J. Deletage, P. Rollin, K. Marchand, T. Lhommeau, and M. Piton, “A first approach on the failure mechanisms of IGBT inverters for aeronautical applications: effect of humidity-pressure combination,” in 2010 IPEC, pp.2450-2465, 2010.

[6] N. Wang, I. Cotton, and K. Evans, "Impact of thermal cycling in humid environments on power electronic modules," IEEE Trans. Compon. Packag. Manuf. Technol., Vol. 2, No. 7, pp.1085-1091, Jul. 2012.

[7] X. Zhang and X. He, "The reliability evaluation of the 
bonding wire in the DC/DC power under the environment of humidity," in 13th International Conference on EPT-HDP, pp.1357-1359, 2012.

[8] H. Chen, Y. Xu, and H. H. C. Iu, "Analysis of temperature distribution in power converter for Switched Reluctance Motor drive,” IEEE Trans. Magn., Vol. 48, No. 2, pp. 991-994, Feb. 2012.

[9] A. Tenconi, F. Profumo, S. E. Bauer, and M. D. Hennen, "Temperatures evaluation in an integrated motor drive for traction applications,” IEEE Trans. Ind. Electron., Vol. 55, No. 10, pp. 3619-3626, Oct. 2008.

[10] B. Du, J. L. Hudgins, E. Santi, A. T. Bryant, P. R. Palmer, and H. A. Mantooth, "Transient electrothermal simulation of power semiconductor devices," IEEE Trans. Power Electron, Vol. 25, No. 1, pp. 237-248, Jan. 2010.

[11] I. Swan, A. Bryant, A. Mawby, T. Ueta, T. Nishijima, and K. Hamada, "A fast loss and temperature simulation method for power converters, Part II: 3-D thermal model of power module," IEEE Trans. Power Electron, Vol. 27, No. 1, pp. 258-268, Jan. 2012.

[12] K. Ma, M. Liserre, F. Blaabjerg, and T. Kerekes, "Thermal loading and lifetime estimation for power device considering mission profiles in wind power converter," IEEE Trans. Power Electron, Vol. 30, No. 2, pp. 590-602, Feb. 2015.

[13] H. Chen and S. L. Lu, "Fault diagnosis digital method for power transistors in power converters of Switched Reluctance Motors,” IEEE Trans. Ind. Electron., Vol. 60, No. 2, pp. 749-763, Feb. 2013.

[14] H. Chen and J. J. Gu, "Implementation of the Three-Phase Switched Reluctance Machine System for motors and generators," IEEE/ASME Trans. Mechatron., Vol. 15, No. 3, pp. 421-432, Jun. 2010.

[15] H. Wang, D. H. Lee, and J. W. Ahn, "Radial force control of a novel hybrid pole BLSRM," Journal of Power Electronics, Vol. 9, No. 6, pp. 845-853, Nov. 2009.

[16] D. H. Lee, J. Liang, and J. W. Ahn, "Series-parallel connected capacitor type boost converter for a single-phase SRM,” Journal of Power Electronics, Vol. 10, No. 4, pp. 388-395, Jul. 2010.

[17] H. K. M. Khoi, J. W. Ahn, and D. H. Lee, "Current control scheme of high speed SRM using low resolution encoder," Journal of Power Electronics, Vol. 11, No. 4, pp. 520-526, Jul. 2011.

[18] M. N. F. Nashed, K. Ohyama, K. Aso, H. Fujii, and H. Uehara, "Automatic turn-off angle control for high speed SRM drives,” Journal of Power Electronics, Vol. 7, No. 1, pp. 81-88, Jan. 2007.

[19] D. H. Jang, "Novel SRM drive systems using variable DC-Link voltage,” Journal of Power Electronics, Vol. 11, No. 3, pp. 285-293, May 2011.

[20] Y. Xu, H. Chen, S. Lv, F. Huang, and Z. Hu, "Thermal model for power converters based on thermal impedance," Journal of Power Electronics, Vol. 13, No. 6, pp.1080-1089, Nov. 2013.

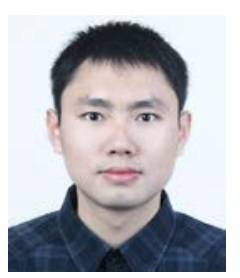

Yang $\mathbf{X u}$ received his B.S. degree in Electrical Engineering in 2009 from China University of Mining and Technology, Xuzhou, China, where he is currently working toward his Ph.D. at the School of Information and Electrical Engineering. His current research focuses on the thermal analysis of power converters.

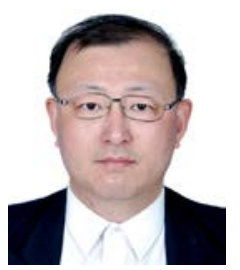

Hao Chen received his B.S. and Ph.D. degrees from the Department of Automatic Control, Nanjing University of Aeronautics and Astronautics, Nanjing, China in 1991 and 1996 respectively. He became an associate professor at the School of Information and Electrical Engineering, China University of Mining and Technology, Xuzhou, China, in 1998, where he has been a professor since 2001. He was a visiting professor at Kyungsung University, Busan, Korea, from 2002 to 2003. He has also been an adjunct professor at the University of Western Australia, Perth, Australia, since 2008. He is the author of one book and more than 180 papers. He has obtained 18 Chinese invention patents and 6 Chinese utility model patents. His current research interests include motor control, electric vehicles, electric traction, servo drives, and wind power generator control. Dr. Chen won an award at the Science and Technology of Chinese Youth and Fok Ying Tong Education Foundation for Youth Teachers both in 2004. He was awarded second prize at the Science and Technology Advanced of Province and Ministry 6 times, as well third prize at the Science and Technology Advanced of Province and Ministry 12 times. He became a National Talent of the Chinese New Century Hundred-Thousand-Ten Thousand Talents Engineering in 2007, and won the Government Special Allowance of the People's Republic of China State Department in 2006.

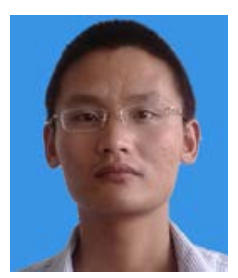

Zhentao Hu received his B.S. degree in 2012 from China University of Mining and Technology, Xuzhou, China, where he is currently working toward his M.S. degree at the School of Information and Electrical Engineering.

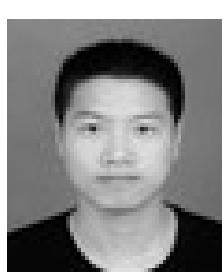

Dong Li received his B.S. degree in 2013 from HuBei University of Automotive Technology, Shiyan, China, where he is currently working toward his M.S. degree at the China University of Mining and Technology, Xuzhou, China. 